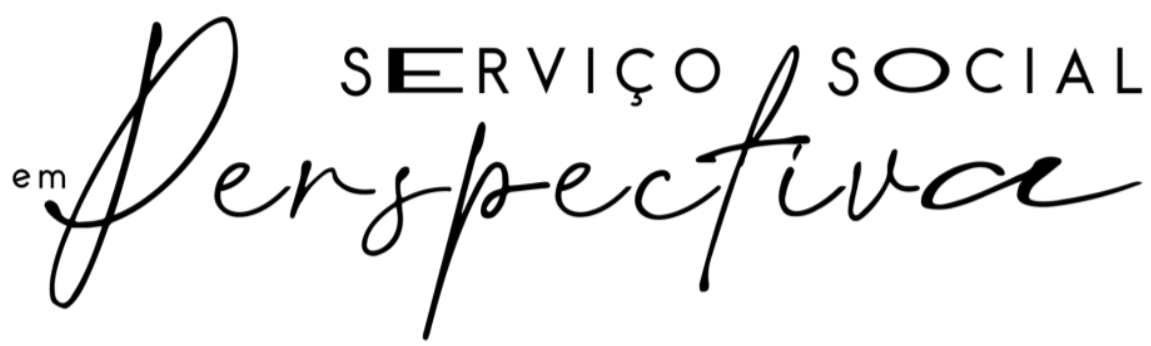

Montes Claros (MG), volume 6, número 1. jan./jun. 2022. I ISSN 2527-1849

\title{
PRECARIZAÇÃO DA ATENÇÃO BÁSICA NO CONTEXTO DE COVID-19
}

\section{PRECARIZACIÓN DE CUIDADOS BÁSICOS EN EL CONTEXTO DE COVID-19}

\author{
Natália Espinosa Pasqualin
}

\begin{abstract}
Resumo: $O$ presente artigo tem por objetivo discutir sobre a precarização da atenção básica $e$ seu agravamento no contexto de Covid-19. Como metodologia teve a revisão bibliográfica e documental acerca da temática, bem como, a sistematização de aspectos públicos da experiência como assistente social residente em uma Unidade de Saúde vinculada a Escola de Saúde Pública/RS. em Porto Alegre. no ano de 2020. contexto de pandemia de Covid-19. Como precarização entendese o conjunto de condições precárias de vida e de trabalho oriundos do processo de agravamento da desigualdade social, especialmente com o advento do neoliberalismo e da Contrarreforma do Estado. Concluiu-se que os processos de privatização da atenção básica impactam e precarizam o cuidado na saúde na medida em que colocam os profissionais em situação de insegurança. prejudicando a criação de vinculos. Essa relação agravou-se no contexto de pandemia, visto que as pessoas estavam passando por novas privações objetivas e subjetivas como desemprego e insegurança financeira. falta de convivência social, medos e ansiedades, etc. A lógica de funcionamento empresarial reduz os atendimentos de saúde na atenção básica a números e metas e. aliado à rotatividade de profissionais, dificulta o vínculo, o acolhimento e a longitudinalidade do cuidado, evidenciando a disputa entre projetos de saúde: democrático conforme os preceitos da Reforma Sanitária e privatista conforme os interesses de mercado.
\end{abstract}

Palavras-chave: Atenção Básica. Precarização. Covid-19.

Resumen: Este artículo tiene como objetivo discutir la precariedad de la atención primaria y su agravamiento en el contexto de Covid-19. Como metodología, se realizó una revisión bibliográfica y documental sobre el tema y también la sistematización de aspectos públicos de la experiencia como trabajadora social residente en una Unidad de Salud vinculada a la Escuela de Salud Pública / RS. en Porto Alegre, en 2020. contexto de la pandemia de Covid-19. Se entiende por precariedad el conjunto de condiciones de vida y de trabajo precarias derivadas del proceso de agravamiento de la desigualdad social, especialmente con el advenimiento del neoliberalismo y la Contrarreforma del Estado. Se concluyó que los procesos de privatización de la atención primaria impactan y precarizan la atención de salud. pues ponen a los profesionales en una situación de inseguridad. dificultando la creación de vínculos. Esta relación se agravó en el contexto de la pandemia, ya que las personas vivian nuevas privaciones objetivas y subjetivas como el desempleo y la inseguridad financiera, falta de interacción social, miedos y ansiedades etc. La lógica del funcionamiento empresarial reduce la atención de la salud en atención primaria a números y metas y. junto a la

\footnotetext{
1 Assistente Social. Graduação em Serviço Social pela Faculdade de Desenvolvimento do Rio Grande do Sul (FADERGS). Residente Multiprofissional em Atenção Básica em Saúde Coletiva pela Escola de Saúde Pública do Estado do Rio Grande do Sul (ESP/RS). Email:natipasqualin@live.com
}

Artigo submetido em: 22 de outubro de 2021.

Artigo aceito em: 22 de dezembro de 2021. p. 108-125, DOI: https://doi.org/10.46551/rssp202206 
rotación de profesionales, dificulta la vinculación, acogimiento y extensión de la atención, resaltando la disputa entre proyectos de salud democráticos según los preceptos de Sanidad y reforma privatista de acuerdo a los intereses del mercado.

Palabras Claves: Atención primaria, Precariedad. Covid-19.

INTRODUÇÃO

Como precarização entende-se uma série de fatores relacionados às condições de trabalho no contexto do capitalismo monopolista. Muitas foram as transformações ocorridas no mundo do trabalho após o rompimento com o padrão fordista baseado na produção em massa e estabelecimento da reestruturação produtiva. $O$ cenário passou de um alto grau de especialização da força de trabalho para flexibilização e acumulação flexível com a exigência de um novo trabalhador adaptado à polivalência do mercado de trabalho. A autora Druck (2011) aponta que as mudanças ocorridas no mundo do trabalho após a década de 1970 favoreceram um aumento da exploração do trabalhador, fato que ela denomina como "espírito do capitalismo reformulado" que carrega em si elementos novos e velhos, metamorfoseandose sem, contudo, abandonar a sua essência que é a extração de mais-valia ${ }^{1}$. Essa precarização torna-se evidente nas condições objetivas de realização do trabalho, tais como: (...) nas formas de inserção e de contrato, na informalidade, na terceirização, na desregulação e flexibilização da legislação trabalhista, no desemprego, no adoecimento (...) etc (DRUCK, 2011. p. 41). No âmbito da saúde pública há dois projetos em permanente disputa, o primeiro, Projeto democrático da Reforma Sanitária (1970) que defende a saúde como direito universal e responsabilidade do Estado, e o segundo, Projeto Privatista neoliberal, hegemônico após a década de 1990, defende a saúde focalizada e voltada aos interesses do mercado. O projeto privatista aponta que o Estado deve garantir um acesso mínimo aos que não podem pagar. oferecendo-lhes um pacote básico de saúde, sendo às suas principais propostas: ampliação da privatização, estímulo ao seguro privado, descentralização dos serviços em nível local e eliminação da vinculação de fonte com relação ao financiamento (CFESS, 2010). A saúde. portanto, constitui uma arena de lutas políticas entre projetos distintos e antagônicos, sendo a atenção básica um dos níveis de atenção em saúde mais importantes pelo seu papel de promoção, prevenção, proteção, diagnóstico, tratamento, reabilitação, redução de danos, cuidados paliativos e recuperação e vigilância em saúde (BRASIL, 2017). A atenção básica 
vem passando por diversas transformações no seu funcionamento, especialmente após a alteração da Política Nacional de Atenção Básica (PNAB) em 2017, onde foi prevista a flexibilização no número de agentes comunitários em saúde e a priorização da chamada atenção básica tradicional em detrimento da estratégia de saúde da família, com maior autonomia e flexibilidade para a gestão municipal, evidenciando que o principal efeito tende a ser o desmonte daquilo que fora conquistado até o momento (MELO, et al, 2018). Em Porto Alegre/RS a atenção básica vem passando por mudanças na gestão e execução após o processo de extinção do Instituto Municipal de Estratégia de Saúde da Família (IMESF), sendo atualmente administrada por empresas com fins filantrópicos como Hospital Divina Providência, Hospital Santa Casa de Misericórdia, Hospital Vila Nova, dentre outros. Para além das transformações referentes ao funcionamento e financiamento da atenção básica, $O$ ano de 2020 colocou outros desafios com a declaração de situação de pandemia de Covid-19. assim decretado pela Organização Mundial de Saúde (OMS) em março daquele ano. Muitas foram as alterações nos fluxos das unidades de saúde e da própria vida no geral, sendo a atenção básica central na para enfrentamento da pandemia, considerando a sua proximidade dos territórios e vínculo com os mesmos. Ao considerar os apontamentos realizados acima, evidencia-se que a questão norteadora deste artigo consiste em analisar quais os impactos da precarização da atenção básica são evidentes no contexto de pandemia de Covid-19 a partir do experienciado como assistente social residente. Experiências são processos históricos e sociais dinâmicos: estão em permanente mudança e movimento. A sistematização de experiência serve como interpretação crítica de uma ou várias experiências que, a partir da sua ordenação e reconstrução, explicita a lógica do processo vivido: os fatores que intervieram, como se relacionam entre si, etc. Tem as seguintes etapas: o ponto de partida, as perguntas iniciais, a recuperação do processo vivido, a reflexão de fundo e os pontos de chegada, evidenciadas na tabela a seguir (HOLIDAY, 2006).

\section{PRECARIZAÇÃO DA SAÚDE: ELEMENTOS PARA O DEBATE}

O mundo do trabalho vem sofrendo diversas alterações ao longo do tempo, especialmente nos últimos 30 anos, em que através dos processos de reestruturação produtiva - mercado de trabalho passou a requerer cada vez mais trabalhadores polivalentes e com vínculos de trabalho fragilizados. O período pós 1970 marcou a criação de diversas estratégias 
de manutenção do capitalismo em sua nova fase da financeirização. Estas estratégias, conforme aponta Montaño (2014) consolidaram-se basicamente em 3 pilares fundamentais: a ofensiva contra o trabalho latingindo às leis e direitos trabalhistas e as lutas sindicais e da esquerda), a chamada "reestruturação produtiva" e a "(contra-) reforma do Estado" (MONTAÑO. 2014, p. 6).

A reestruturação produtiva trouxe mudanças nas formas de produzir e organizar o trabalho que visavam consolidar o modelo industrial flexível. Este novo cenário precarizou as relações de trabalho, sendo esta precarização evidente através de indicadores como: vulnerabilidade das formas de inserção e desigualdades sociais; intensificação do trabalho e terceirização, insegurança e saúde no trabalho, perda das identidades individual e coletiva, fragilização da organização dos trabalhadores e, por fim, a condenação e o descarte do Direito do Trabalho, (DRUCK, 2011). Mediante a constante ameaça de desemprego os trabalhadores se vêem obrigados a aceitar as condições precárias de trabalho criadas pelo capitalismo, afinal, ter um emprego é melhor que não ter nenhum, (DRUCK, 2011). Pelo que indica a Organização Internacional do Trabalho (2006) depois de uma década, a experiência de vários países mostra que, apesar dessas reformas, em lugar do aumento do emprego formal, o que se produziu foi um incremento do desemprego e da informalidade, com aumento da desproteção social.

A reestruturação produtiva foi um processo com dimensão política, social e cultural, assim, suas mudanças não só ocorreram na produção em si, mas também na correlação de forças entre capital e trabalho e no redirecionamento do papel do Estado, (NOVAIS: SANTOS, 2017). Este redirecionamento do Estado ficou conhecido como (contra) Reforma do Estado, que consiste em uma série de medidas que objetivam a diminuição dos gastos públicos, sendo elaboradas a partir do projeto intelectual de Bresser Pereira (1997). De acordo com Behring e Boschetti (2011) essa fase conhecida como contrarreforma do Estado ocorrida a partir dos anos 1990 se deu a partir das formulações do Plano Diretor da Reforma do Estado, amplamente afinado com as formulações de Bresser Pereira, na época à frente do Ministério da Administração e da Reforma do Estado (MARE).

A palavra reforma foi historicamente relacionada às lutas da classe trabalhadora e a perspectiva de ampliação de direitos sociais, sendo cooptada pela ideologia neoliberal para justificar o combate às dimensões democráticas do Estado, resultando em contrarreformas com o objetivo de reduzir ou eliminar direitos conquistados (SIMIONATO; LUIZA, 2011). 
Assim, tem-se inicio à contrarreforma do Estado: um conjunto de medidas neoliberais e destruição das conquistas democráticas. Nessa perspectiva, floresce a crença de que a Reforma do Estado deve-se dar-se no âmbito quantitativo, fiscal, financeiro e gerenciador, em detrimento do político, participativo e democrático, ou seja, o Estado estaria submetido aos ditames de uma nova era histórica e universal, a globalização. que por meio da desregulamentação, reduziria consideravelmente o papel político e participativo do próprio Estado e da sociedade (MACIEL, 2017, p. 4).

De acordo com Behring (2003) para Bresser Pereira (1996) o Estado social-liberal se dá no comprometimento ora com a implementação dos direitos sociais do século XIX, ora com o mercado, pois o Brasil passou a integrar o processo de globalização, orientando suas reformas para o mercado. A contrarreforma do Estado teve diversos impactos nas políticas públicas e sociais, pois, ao incorporar os interesses do mercado e construir narrativas em torno da relação de participação da sociedade civil e do Estado, favoreceu o surgimento das Organizações Sociais e das (OSs) e das Organizações Sociais da Sociedade Civil de Interesse Público (OSCIPs). Essas instituições surgem a partir do apelo moral e colaboracionista voltado ao desenvolvimento social com ênfase na sociedade civil.

A privatização como resultado dos processos de contrarreforma do Estado afetou uma série de políticas sociais, como é o exemplo da assistência social, operacionalizada em suas diferentes complexidades por organizações sociais em sua maioria de cunho religioso. No cenário de Porto Alegre/RS, em relação aos abrigos e casas lares que acolhem crianças e adolescentes, de 83 instituições 76 são parceirizadas, considerando a substituição da execução direta do municipio para as OSCIPs, revelando a tendência à terceirização presente desde 1990 (BENTO, 2019).

A mesma tendência ocorre em relação à rede de educação infantil do município e à saúde, especialmente a atenção básica. Estes dados se relacionam com o contexto no geral, que apresenta a mesma tendência de diminuição do papel do Estado frente ao proposto pela Constituição Federal de 1988, que garante em seu artigo sexto que: "são direitos sociais a educação, a saúde, o trabalho, o lazer, a segurança, a previdência social, a proteção à maternidade e à infância, a assistência aos desamparados". Em relação à saúde cada vez mais se utiliza desta política como fonte de investimento e lucratividade capitalista, tornando-a uma cadeia de mercadorias e negócios rentáveis, como através da indústria de medicamentos, 
equipamentos médico-hospitalares e insumos, planos privados, redes de hospitais, etc, (SOARES, 2013 apud MACIEL, 2017).

No âmbito da saúde, foi a partir da consolidação da Constituição Federal de 1988 que esta política passou a ser um direito universal e dever do Estado, devendo ocorrer de maneira regionalizada e hierarquizada. Está amparada pela Lei 8.080/90 e pela 8.142/90 que visa promover a qualidade dos serviços prestados, democratização do acesso, integralidade e equidade nas ações, assim como a participação popular. A Lei 8080/90, que dispõe sobre as condições para promoção, proteção e recuperação da saúde, a organização e o funcionamento dos serviços correspondentes e dá outras providências, aponta que a participação complementar dos serviços privados será formalizada mediante contrato ou convênio, observadas, a respeito, as normas de direito público. Na hipótese do artigo anterior, as entidades filantrópicas e as sem fins lucrativos terão preferência para participar do Sistema Único de Saúde (SUS) (BRASIL, 1988).

No entanto, embora esteja previsto participação da iniciativa privada de forma apenas complementar, o que se percebe é a permanente disputa entre estes modelos de saúde, que constitui o projeto da Reforma Sanitária e o Projeto Privatista. Em relação a estes projetos Bravo e Marques (2013) sinalizam que o primeiro compreende a saúde como um direito social e dever do Estado e o segundo como uma prática mercantilista, visto os avanços das privatizações através das organizações sociais e fundações estatais de direito privado, na defesa do Estado social mínimo.

Essa disputa evidencia-se através de questões como na restrição de verbas para o SUS e sua consequente incapacidade de promover a universalidade do acesso, restando um serviço pauperizado e de acesso somente das classes subalternas, reiterando a lógica de que aquilo que vem do Estado é inferior ao que vem do mercado. Em relação ao desinvestimento no SUS destaca-se a aprovação da PEC 55/16. "Novo Regime Fiscal", que congelou os gastos com a seguridade social durante 20 anos.

Percebe-se que os direitos historicamente conquistados como a saúde enfrentam adversidades relacionadas ao contexto social e econômico. No sistema capitalista, mesmo em épocas de abertura democrática e reforma do Estado, o Capital se reorganiza para implementar novas formas de exploração da classe trabalhadora e isentar o Estado de suas responsabilidades na garantia de condições de vida para a mesma, como é o exemplo das 
contrarreformas no âmbito dos direitos sociais e nas politicas públicas iniciadas a partir da década de 1990. Hoje a saúde encontra-se no ápice dos impactos oriundos deste processo de precarização, e seus mecanismos de gestão inovadores propostos na Lei 8142/90, que são os Conselhos de Saúde e Conferências de Saúde estão sendo cada vez mais invisibilizados. Portanto, resta a necessidade de defesa do SUS tal qual ele é proposto inicialmente, como direito social universal e responsabilidade do Estado, bem como, dos espaços de participação social como potências de denúncia e transformação.

PERCEPÇÕES DA PRECARIZAÇÃO A PARTIR DO COTIDIANO NA RESIDÊNCIA INTEGRADA EM SAÚDE

O Sistema Único de Saúde (SUS) organiza-se através de níveis de complexidade, sendo a atenção básica o primeiro nível de cuidado em saúde. É considerada a porta de entrada para o SUS devendo se orientar pelas diretrizes a universalidade, equidade e integralidade, e pelos principios de regionalização e hierarquização, territorialização, população adscrita, cuidado centrado na pessoa, resolutividade, longitudinalidade do cuidado, coordenação do cuidado, ordenação da rede e participação da comunidade. Faz parte do processo de reorientação do modelo de saúde no Brasil, devendo pautar-se na adscrição de um território específico para planejamento e construção de suas ações em saúde.

Em 2006 foi publicada a primeira versão da Política Nacional de Atenção Básica (PNAB) com a Portaria no 648 de 28 de Março de 2006, posteriormente revogada pela Portaria no 2.488 de 21 de outubro de 2011. A PNAB de 2006 estabeleceu importantes avanços ao atribuir à familia e à comunidade um papel de centralidade no cuidado em saúde, através das Estratégias de Saúde da Família (ESF) e posteriormente a criação dos Núcleos de Apoio à Saúde da Familia (NASF) pelo Ministério da Saúde, através da Portaria GM no 154, de 24 de janeiro de 2008, republicada em 4 de março de 2008. Os NASFs foram criados com o objetivo de apoiar a inserção da ESF na rede de serviços, bem como, ampliar o escopo de ações da atenção básica através do trabalho multidisciplinar e de matriciamento em saúde (BRASIL. 2009)

aumento do escopo de intervenção e consequente aumento da resolutividade devese a ampliação das equipes e da inserção de profissionais como assistentes sociais, psicólogos, 
fonoaudiólogos, dentre outros. Os NASF fazem parte da atenção básica, mas não se constituem como serviços com unidades físicas e independentes ou especiais (BRASIL, 2017). A PNAB de 2011 seguiu na mesma linha de expansão e qualificação da AB com a criação do Programa Saúde na Escola (PSE), Consultório na Rua, das novas modalidades de equipes, como às ribeirinhas, fluviais, etc, bem como a informatização das unidades com o Requalifica UBS.

Em contrapartida a esse movimento de expansão e qualificação, foi publicada uma atualização da PNAB através da Portaria no 2.436 de 21 de setembro de 2017. Em um sentido geral, a PNAB de 2017 permaneceu com as mesmas diretrizes da anterior, porém com menos ênfase à educação permanente e com uma flexibilização em relação ao número de agentes comunitários de saúde, passando a ser exigido somente um por equipe de saúde da familia. Em 2019 foi publicado o novo financiamento da atenção básica, intitulado "Previne Brasil" pela Portaria no 2.979, de 12 de novembro de 2019.

O novo modelo de financiamento altera algumas formas de repasse das transferências para os municípios, que passam a ser distribuidas com base em três critérios: captação ponderada, pagamento por desempenho e incentivo para ações estratégicas. $\bigcirc$ repasse de recursos se pauta no número de pessoas cadastradas e no atingimento de metas e indicadores e tem como pressuposto o aumento do número de cadastramento de pessoas vinculadas às equipes de saúde da família e a sua consequente responsabilização, porém, isso restringe mais ainda o acesso ao não considera os municípios com dificuldades no cadastramento, por falta de recursos humanos ou por falta de acesso da população (BRASIL, 2019).

Em Porto Alegre/RS a atenção básica vem enfrentando uma série de desmonte desde a extinção do Instituto Municipal de Estratégia de Saúde da Familia (IMESF) que teve início em 2017 através de uma ação direta de inconstitucionalidade (ADIN). Desde então se iniciou um processo de contratualização das unidades, que passaram a ser administradas por instituições filantrópicas de direito privado.

Este processo resultou em grande rotatividade de profissionais contratados, prejudicando a continuidade do cuidado e a construção de vínculos com a população. Em relação à privatização da atenção básica é importante destacar o papel do Conselho Municipal de Saúde de Porto Alegre/RS que vem se posicionando criticamente frente à estes retrocessos, como se percebe através da publicação da "Nota Pública sobre a situação da Saúde da Familia em Porto Alegre" que aponta o indicativo de terceirização de cerca de 77\% 
da atenção básica de Porto Alegre, envolvendo aproximadamente 15 milhões de repasse mensal à entidades privadas. De acordo com o CMS/POA a máxima da gestão atual de "menos Estado e mais Saúde" e de, a qualquer custo, levar adiante o projeto de empresariamento da Saúde ferem frontalmente a Constituição Federal que preconiza a Saúde como dever do Estado e direito do cidadão.

Os impactos desta precarização no cotidiano de funcionamento das unidades de saúde implicam em questões como: funcionamento na lógica empresarial com metas de produção mensais como condição para o financiamento, rotatividade de profissionais, falta de qualificação em relação aos objetivos da atenção básica, dentre outras. Com a extinção do IMESF ocorreu também a demissão dos Agentes Comunitários de Saúde (ACS) e Agentes de Combate à Endemia (ACE). Destacando-se que a ausência dos agentes comunitários de saúde, profissionais moradores do território adscrito, fere diretamente o princípio do vínculo com o território e dificulta sobremaneira a construção do diagnóstico da comunidade e portanto a identificação das áreas e riscos individuais e coletivos e próprio cadastramento das famílias, transformando em metas com fim em si mesmas.

Na US campo da residência durante o ano de 2020 havia apenas um ACS atuante vinculado ao IMESF e dois outros, um afastado por comorbidade em relação à Covid-19 e outro que aceitou o acordo de demissão do IMESF. $O$ único que ACS atuante acabou por contrair Covid-19 e ficou afastado um período. Na área de abrangência da US estavam cadastrados apenas 3.007 pessoas (dado de Julho de 2020) para um contingente populacional de 18.491 mil, ou seja, havia um déficit muito grande na vinculação das pessoas às equipes, o que foi mudando durante o ano devido à cobrança para o repasse de recursos. Ocorre que o cadastramento e vinculação no sistema E-SUS era atividade dos ACS e passou a ser feito na recepção da US pelos recepcionistas contratados, entre eles o próprio ACS que no final de 2020 aceitou a proposta de demissão do IMESF (em processo de extinção) e passou a trabalhar vinculado à entidade filantrópica no cargo de recepcionista (porém permaneceu realizando atividades como visita domiciliar, etc). Ou seja, permaneceu como referência para os usuários e para a equipe, porém sem a estabilidade do concurso público. Muitos profissionais fizeram esse mesmo trajeto de migrar para a contratualização como alternativa de manterse empregado, o que evidencia a precarização como estratégia politica de gestão do trabalho em saúde. 
O ACS é o profissional elo entre o território e a equipe, e território deve ser compreendido para além de um espaço/adstrição para fins administrativos e gerenciais, evitando a limitação do seu "potencial e suas possibilidades na identificação de questões de saúde e das correspondentes iniciativas de intervenção concreta na realidade cotidiana das coletividades humanas", (SANTOS; RIGOTTO, 2010, p. 389).

É neste cenário de descontinuidade que se inserem os profissionais residentes vinculados ao Programa de Atenção Básica em Saúde Coletiva, que conforme o itinerário formativo devem permanecer na Unidade de Saúde durante o primeiro ano da residência. Ocorre que no campo de prática desta experiência aconteceram diversas demissões, pedidos de remanejamento, novas contratações, sendo possivel acompanhar diversos processos de abandono: dos usuários que perderam referências (muitas vezes sem aviso prévio) e da equipe que ficou e teve que se reorganizar com os agendamentos e atendimentos de demanda espontânea. Foi possivel ver cotidianamente o desmonte dos vínculos, principal potência da atenção básica, que se operacionaliza através das relações e que acontece através do que Merhy (2002) define como tecnologias leves, construidas a partir do encontro terapêutico profissional-usuário.

Ocorre que nesse encontro entre profissional de saúde e usuário se estabelecem relações de confiança e identificação. Quando essa relação é interrompida abruptamente geram-se processos de desconfiança e sofrimento causando até a interrupção dos acompanhamentos. Narrar novamente suas dores e sua história se torna um percurso cansativo podendo afastar a pessoa do serviço de saúde ou até revitimizá-la. Também, pode ser que a pessoa apenas oculte aspectos elaborados anteriormente em atendimento e busque 0 serviço apenas para demandas pontuais ou que envolvam atendimentos prescritivos: renovação de receitas, retirada de medicamentos de uso contínuo, etc. Por que falar de si quando quem escuta não permanece?

Todas estas questões agravaram-se no contexto da pandemia de Covid-19 ocasionando diversas alterações na vida das pessoas e também no funcionamento dos serviços de saúde. Desta forma, levando em consideração a amplitude da atenção básica e suas possibilidades de ação junto ao território, faz-se necessário discutir o lugar da Atenção Primária à Saúde (APS) no enfrentamento a pandemia, uma vez que os estudos indicam que cerca de $80 \%$ dos 
casos são leves e que grande parte dos casos moderados procuram a rede básica como primeiro acesso na busca de cuidados, (SARTl,et al, 2020).

Foram estabelecidos fluxos específicos de triagem e acolhimento dos casos sintomáticos e suspeitos de Covid-19 em uma sala específica com os profissionais escalados para tal, devendo atuar devidamente protegidos com EPIs como avental, máscara N95, faceshield, etc. Os fluxos e orientações quanto aos sintomas, testagem e monitoramento de casos foram sendo construidos e publicados durante a pandemia de maneira bem dinâmica, destacando-se o papel da Vigilância em Saúde na figura do Centro de Operações Especiais (COE) do Centro Estadual de Vigilância em Saúde (CEVS). Foram muitas mudanças durante esse um ano de residência exigindo reelaboração constante nas orientações dadas à população, sendo estas notas técnicas sempre debatidas nas reuniões de equipe.

Por se tratar de um território bastante vulnerável, em alguns pontos sem acesso à saneamento básico ou com faltas constantes de água, tornava-se difícil o cumprimento das medidas sanitárias e de distanciamento social recomendados pelas autoridades públicas. Muitas familias com mais de 5 membros residentes em um mesmo domicílio, dormindo no mesmo cômodo/cama, gerava uma série de casos positivos para Covid-19. A testagem, quase sempre em local distante à residência, era também um processo complicado para algumas famílias. Destaca-se a Nota Informativa 33 CEVS/SES de março de 2020, atualizada em fevereiro de 2021. que dispõe sobre a Vigilância de Síndrome Gripal (SG) e Síndrome Respiratória Aguda Grave (SRAG) relacionada à infecção humana pelo COVID-19, sistemas de notificação, rede laboratorial e estratégias de testagem. A US não realizava os testes de Covid-19, apenas avaliava, notificava e acompanhava em caso de sintomas leves.

Sabe-se que de um modo geral o Brasil e os demais países têm adotado como estratégia principal para conter a crise: distanciamento social, testagem e oferta de leitos hospitalares para pessoas com Covid-19, sobretudo nas Unidades de Tratamento Intensivo (UTI), destacando a criação dos hospitais de campanha, a construção e reparo de respiradores e outros equipamentos; compra de insumos; contratação emergencial de profissionais e capacitações para sua atuação, (SEIXAS, et al, 2021). Considerando a centralidade atribuida ao âmbito hospitalar no combate à pandemia, questiona-se, qual seria então o papel da atenção básica neste momento? 
Há diversas ações que seriam essenciais da atenção básica realizar no nesse contexto de pandemia. Uma delas que seria estratégica e essencial é a realização de ações de educação em saúde, incluidas: uso correto da máscara, etiqueta respiratória, principais sintomas, fluxos de testagem e isolamento, sintomas leves e graves e onde buscar atendimento em caso de agravo, desmistificação das chamadas fake news, etc. Todas essas orientações devendo estar de acordo com os protocolos sanitários estabelecidos pelos órgãos competentes. $\bigcirc$ Conselho Municipal de Saúde procurou levantar esse debate em diversas plenárias, como na realizada no dia 18 de março de 2021 que teve como temática central a situação da pandemia na Atenção Básica e o Plano de Ação para fortalecimento da Atenção Básica no enfrentamento à Covid-19.

No cotidiano o que foi possivel realizar, considerando a sobrecarga dos profissionais, - déficit de direitos humanos causado pelas constantes demissões e afastamentos de saúde. foi a orientação por whatsapp sobre sintomas e testagem, o acolhimento presencial e por telefone das demandas relacionadas ao Covid-19, como orientações sobre isolamento social, afastamento do trabalho e atestados médicos, etc. Em âmbito coletivo poucas ações foram realizadas, destacando a produção de materiais visuais de orientações de saúde enviados para a população através dos conselheiros locais de saúde. Neste ponto a ausência de agentes comunitários de saúde foi extremamente sentida.

Para além das questões de atendimentos de manejo dos sintomas da Covid-19. que acontecem em fluxos que obedecem ao distanciamento mínimo e isolamento dos sintomáticos respiratórios, também há o papel da atenção básica de abordar problemas do isolamento social prolongado e da precarização social e econômica, como a agudização de problemas como violência doméstica, alcoolismo, ansiedade, depressão, etc.

Estima-se, que entre um terço e metade da população exposta a uma epidemia pode vir a sofrer alguma manifestação psicopatológica, caso não seja feita nenhuma intervenção de cuidado específico para as reações e sintomas manifestados, (FIOCRUZ, 2020). Porém. devido aos fatores enunciados como a precarização da atenção básica, muitas possibilidades de atuação durante a pandemia tornam-se restritas. Isto se deve ao quadro rotativo de profissionais, que acarreta na dificuldade de construção de vínculo e de ações de promoção de saúde condizentes com o perfil da população, da falta de ACS e ACE, elos importantes com a comunidade 
foco de investimento como resposta sanitária à pandemia tem sido os hospitais e unidades de tratamento intensivo. São importantes no contexto, no entanto, é preciso estender este olhar e investimento à atenção básica justamente pelo seu potencial de promoção e prevenção. Torna-se essencial evidenciar que pandemias como a de Covid-19 colocam em xeque discursos e práticas de redução do tamanho do Estado, flexibilização das leis trabalhistas, desmonte do sistema de proteção social, desvalorização e desinvestimento em ciência, tecnologia e ensino, e de precarização de serviços públicos de saúde". ISARTI, et al 2020).

Segue uma sistematização da experiência considerando aspectos relacionais dos atores envolvidos e como eles foram percebidos no cotidiano profissional, considerando a precarização e sua agudização no contexto de pandemia.

Tabela 1 - Sistematização da experiência.

\begin{tabular}{|c|c|c|}
\hline \multicolumn{3}{|c|}{ Sistematização de experiência } \\
\hline Principais aspectos: & Percepções no cotidiano: & E na pandemia? \\
\hline $\begin{array}{l}\text { Relação entre usuários e } \\
\text { profissionais de saúde }\end{array}$ & $\begin{array}{l}\text { Muitos vínculos foram } \\
\text { dificultados pela alta } \\
\text { rotatividade de profissionais, } \\
\text { o que gerou sofrimento aos } \\
\text { usuários na medida em que } \\
\text { interrompeu um processo } \\
\text { terapêutico ou uma relação } \\
\text { de confiança }\end{array}$ & $\begin{array}{l}\text { A relação foi atravessada } \\
\text { pela insegurança e o medo de } \\
\text { transmitir ou contrair o vírus } \\
\text { da Covid-19, sendo } \\
\text { necessário cumprir os } \\
\text { protocolos sanitários como } \\
\text { distanciamento e uso de EPIs } \\
\text { (o que impacta na criação de } \\
\text { vínculos). Aliado às restrições } \\
\text { de circulação na US e a } \\
\text { rotatividade de profissionais } \\
\text { é possivel afirmar que o } \\
\text { vínculo se tornou algo } \\
\text { bastante inviabilizado. }\end{array}$ \\
\hline $\begin{array}{l}\text { Relação entre a equipe } \\
\text { multiprofissional }\end{array}$ & $\begin{array}{l}\text { Vínculos frágeis, trabalho } \\
\text { médico-centrado, } \\
\text { competitividade e baixa } \\
\text { cooperação. }\end{array}$ & $\begin{array}{l}\text { A relação entre a equipe e } \\
\text { os residentes foi sempre } \\
\text { dificultada pelo não } \\
\text { entendimento do papel da } \\
\text { residência na US e entre a } \\
\text { própria equipe a cooperação } \\
\text { era baixa devido às }\end{array}$ \\
\hline
\end{tabular}


cobranças por atingimento de metas, ao excesso de demandas, cansaço físico e mental, etc.

\begin{tabular}{|c|c|c|}
\hline $\begin{array}{l}\text { Relação da } A B \text { com os } \\
\text { serviços da rede intersetorial } \\
\text { no território }\end{array}$ & $\begin{array}{l}\text { Relação pouco articulada, } \\
\text { com participação em poucos } \\
\text { espaços intersetoriais e } \\
\text { Ocorreu principalmente por } \\
\text { meios virtuais, com exceção } \\
\text { do CRAS e do Conselho } \\
\text { Tutelar que em centrada nos } \\
\text { residentes como principais } \\
\text { responsáveis de realizar } \\
\text { essas articulações, com } \\
\text { Conselho Tutelar, CRAS, } \\
\text { CREAS, SCFV, etc. }\end{array}$ & $\begin{array}{l}\text { Ocorreu principalmente por } \\
\text { meios virtuais, com exceção } \\
\text { do CRAS e do Conselho } \\
\text { Tutelar que em algumas } \\
\text { situações pontuais realizaram } \\
\text { reuniões e intervenções } \\
\text { presenciais. }\end{array}$ \\
\hline $\begin{array}{l}\text { Relação com os princípios e } \\
\text { diretrizes da } A B\end{array}$ & $\begin{array}{l}\text { Princípio da Universalidade } \\
\text { efetivado através do } \\
\text { acolhimento de todas as } \\
\text { demandas espontâneas e } \\
\text { programadas, porém, a } \\
\text { longitudinalidade do cuidado } \\
\text { prejudicada devido alta } \\
\text { rotatividade de profissionais. }\end{array}$ & $\begin{array}{l}\text { A pandemia impactou } \\
\text { diretamente na efetivação } \\
\text { do princípio da integralidade } \\
\text { do cuidado na medida em que } \\
\text { diversos aspectos seriam } \\
\text { importantes e necessários, } \\
\text { como o grupo de saúde } \\
\text { mental que funcionava na US. }\end{array}$ \\
\hline
\end{tabular}

Elaborado pela autora (2021)

Entre os aspectos percebidos, a longitudinalidade do cuidado é o mais dificultado devido à rotatividade de profissionais. Trata-se do acompanhamento do usuário ao longo do tempo por profissionais da atenção básica em que se espera uma relação terapêutica que envolva a responsabilidade por parte do profissional de saúde e a confiança por parte do usuário. Este atributo é constituido por três elementos: a existência e o reconhecimento de uma fonte regular de cuidados, o estabelecimento de vínculo terapêutico duradouro entre os usuários e os profissionais de saúde da equipe local e a continuidade informacional. (NUNES et al, 2016). Esses três pontos relacionados à longitudinalidade não foram possíveis na maioria dos casos observados pela residente na US, havendo situações em que pessoas com quadros graves de saúde mental tiveram seu vínculo interrompido de um dia para o outro. $\bigcirc$ manejo das agendas era constante para adequação às demissões, e no mais, situações que estavam 
sendo acompanhadas por profissionais sob a ótica da integralidade perdiam o fio condutor quando os mesmos saiam, principalmente em relação a situações de abuso sexual e violências.

No que se refere à relação com os demais serviços da rede socioassistencial notouse uma atuação bem isolada da US neste periodo, com pouca comunicação principalmente com a assistência social e a educação. Neste sentido, os residentes da US tinham um papel fundamental na articulação com as demais políticas. A relação entre a equipe era contraditória, em alguns momentos de cooperação e trabalho multiprofissional mas grande parte das vezes permeada de competitividade e atritos.

Conselho Local de Saúde esteve inativo durante boa parte do ano de 2020. Tentouse realizar as reuniões virtuais porém teve pouca adesão. O Conselho Municipal de Porto Alegre (CMS/POA), no entanto, realizou todas as plenárias de forma online, sendo possivel participar de boa parte delas como carga horária complementar da residência. Nas atividades do CMS/POA a pauta atenção básica foi debatida diversas vezes onde se evidenciou a situação de precarização dos serviços da atenção básica e dos trabalhadores da saúde. especialmente os agentes comunitários de saúde. Foi publicado em novembro de 2020 um "Manifesto em defesa da Atenção Básica pública, universal e de qualidade". Nele consta crítica ao Estado como mero regulador e gerenciador de contratos, onde a Politica de Saúde passa a ser tratada como um negócio digno de empresariamento.

\section{CONSIDERAÇÕES FINAIS}

A atenção básica tem sido considerada imprescindivel para a melhora das condições de saúde da população. Alguns fatores relacionados a esse papel são a proximidade do local onde as pessoas moram e vivem, o vínculo estabelecido a partir desse território determinado e seu reconhecimento, a presença dos profissionais agentes comunitários de saúde e agentes comunitários de endemias, a presença de uma equipe multiprofissional de referência, etc. Todos esses aspectos operacionalizam as diretrizes estabelecidos na PNAB, que são de territorialização, população adscrita, cuidado longitudinal e centrado na pessoa, dentre outras, (BRASIL, 2017). De todos os niveis de assistência à saúde a atenção básica é aquele em que o cuidado se operacionaliza de maneira mais longitudinal. Onde é possível, em tese, acompanhar 
situações por um periodo de tempo maior, combinando intervenções de promoção, prevenção e recuperação da saúde.

Durante a pandemia de Covid-19 à atenção básica caberiam ações como mapeamento dos grupos de risco e telemonitoramento, realização de ações de educação em saúde, especialmente em relação às formas de prevenção da contaminação, disseminação e manejo dos sintomas, fluxos de testagem, etc. No entanto, considerando a sobrecarga de atendimentos programados (como puericultura, pré-natal, saúde mental, etc) muitas ações não foram possiveis. A este cenário soma-se o alto nível de rotatividade dos profissionais (por demissão ou por realocação de Unidade de Saúde) e o grande número de afastamentos por infecção ou suspeita de contaminação por Covid-19, gerando um déficit constante nos recursos humanos necessários para realização dessas ações.

Esses impeditivos surgiram também do processo de privatização das Unidades de Saúde, gerando diversas formas de precarização, sejam elas relacionadas diretamente ao trabalhador ou a população usuária, que passou a enfrentar uma descontinuidade nos acompanhamentos. A partir da experiência como residente foi possivel identificar os principais desdobramentos da disputa entre os projetos de saúde pública e saúde privada a nível local, com impactos concretos em um território determinado e na vida de diversas pessoas, situação que se agravou ainda mais durante a pandemia de Covid-19. Conclui-se, então, a necessidade de defesa do SUS nos moldes em que a Reforma Sanitária propôs: público, universal, regionalizado e dividido em niveis de complexidade necessários para a garantia da assistência à saúde de maneira integral, cabendo à atenção básica o papel de porta de entrada e ordenação da rede de atenção à saúde, bem como, da participação da comunidade como fator necessário, como vem se mostrando o Conselho Municipal de Saúde ao e denunciar esses processos de precarização.

\section{REFERÊNCIAS BIBLIOGRÁFICAS}

BARICATI, Crysthiane C. A longitudinalidade do cuidado na atenção básica à luz da experiência dos usuários com hipertensão arterial. Universidade Estadual de Londrina, Tese de Doutorado. Londrina, 2016. Disponivel em: $\langle$ http://www.bibliotecadigital.uel.br/document/?code=vt/s000204849>. Acesso em: 20 de setembro de 2021. 
BEHRING. Elaine Rosseti; BOSCHETTI, Ivanete. Política Social: fundamentos e história. 9 ed. São Paulo: Cortez, 2011.

BENTO. Micheli Viegas. Análise sócio-histórica da institucionalização da Infância às medidas de proteção: o acolhimento institucional em Porto Alegre na realidade brasileira. Universidade Federal do Rio Grande do Sul (UFRGS). Trabalho de Conclusão de Curso (TCC). Porto Alegre, 2019

BRASIL. Constituição (1988). Constituição da República Federativa do Brasil. Brasilia, DF: Centro Gráfico, 1988

BRASIL. Política Nacional de Atenção Básica. Brasília. Brasília, DF, 2017.

BRASIL. Lei no 8080 de 19 de setembro de 1990. Dispõe sobre as condições para a promoção, proteção e recuperação da saúde, a organização e o funcionamento dos serviços correspondentes e dá outras providências. Diário Oficial da União, Poder Executivo, 1990, Set. 20 .

BRAVO, Maria Inês Souza; MARQUES, Morena Gomes. Saúde e luta sindical: entre a reforma sanitária e o projeto de saúde privatista. In: BRAVO. Maria Inês Souza; MENEZES, Juliana Souza Bravo de (Orgs.). Saúde, serviço social, movimentos sociais e conselhos: desafios atuais. 2. ed. São Paulo: Cortez, 2013. p. 197-227.

CONSELHO FEDERAL DE SERVIÇO SOCIAL (CFESS). Parâmetros para atuação de assistentes sociais na saúde. Brasília, 2010.

CONSELHO MUNICIPAL DE SAÚDE DE PORTO ALEGRE/RS. MANIFESTO - Em defesa da Atenção Básica pública, universal e de qualidade: O Sistema Único de Saúde (SUS) é o maior patrimônio do povo Brasileiro.

$\langle h+t p: / / w w w 2$ portoalegre.rs.gov.br/cms/default.php?reg=440E_p_secao=8> Acesso em: 30 de setembro.

DRUCK, Graça. Trabalho, precarização e resistência: novos e velhos desafios. CADERNO CRH, Salvador, v. 24, n. 01, p. 37-57, 2011.

FUNDAÇÃO OSWALDO CRUZ (FIOCRUZ). Saúde mental e atenção psicossocial na pandemia de Covid-19. Brasilia, DF, 2020.

MACIEL, Sergiane M. Reforma (Contrarreforma) do Estado: reflexos na política de saúde. VIII Jornada Internacional de Politicas Públicas, São Luís - Maranhão, 2017.

MARX, Karl. O Capital. Crítica da Economia política. Volume II. O processo de circulação do Capital. Coord. Paul Singer. Editado por Friedrich Engels. Traduzido por Regis Barbosa e Flávio R. Kothe. Editora Nova Cultural, São Paulo, 1985. 
MELO, Eduardo A. MENDONÇA, Maria Helena M. OLIVEIRA, Jarbas R. ANDRADE, Gabriella C. L. Mudanças na Politica Nacional de Atenção Básica: entre retrocessos e desafios. Revista Saúde e Debate, V. 42. Número Especial, 1. P. 38-51. Rio de Janeiro, 2018.

MERHY, Emerson Elias. Saúde, a cartografia do trabalho vivo. São Paulo: Hucitec, 2002.

MONTAÑO. Carlos. Configurações da crise capitalista e incidências no mundo do trabalho. In: CRESS-MG (Orgs) Revista Conexão Geraes ,n. 5, 20 semestre, 2014.

NOVAIS, Liliane C.C. SANTOS, Fernando R.S. Estrutura da Contrarreforma do Estado e seus impactos nas Políticas Sociais: o caso de Mato Grosso (2995-2006). VII Jornada Internacional de Políticas Públicas, São Luís, Maranhão, 2015.

SARTI, Thiago D. LAZARINI, Wellington S. FONTENELLE, Leonardo F. ALMEIDA, Ana Paula S.C. Qual o papel da Atenção Primária à Saúde diante da pandemia provocada pela COVID-19?. Revista Epidemiol. Serv. Saúde, Brasilia, 2020.

SANTOS, Alexandre; RIGOTTO, Raquel. Território e territorialização: incorporando às relações produção, trabalho, ambiente e saúde na atenção básica à saúde. Trab. Educ. Saúde, Rio de Janeiro, v. 8 n. 3, p. 387- 406, nov. 2010/fev.2011.

SIMIONATO. Estado e sociedade civil em tempos de contrarreforma: lógica perversa para as políticas sociais. Revista Textos e Contextos, V. 10, p.G. 215-216, Porto Alegre, 2011.

SEIXAS, Clarissa T. MERHY, Emerson E. FEUERWERKER, Laura CM. SANTO, Tiago BE. JÚNIOR, Helvo S. CRUZ, Kathleen T. A crise como potência: os cuidados de proximidade e a epidemia pela Covid-19. Revista Interface, Botucatu, São Paulo, 2021. Disponivel em: Acesso em: 30 de setembro de 2021. 